\title{
nature
}

\section{Policing ourselves}

\author{
Biologists should push forward with an effort that began in California last \\ weekend to wrestle with the implications of synthetic biology.
}

\rceil here are many ways of measuring the importance of a scientific discipline, and most would lead you to dismiss synthetic biology as a pretty marginal affair. It has yet to produce a profusion of great papers, to underpin vibrant new businesses, to generate stereotypes in the public imagination, to benefit from vast flows of grant money, or to boast a substantial body of practitioners united in their vision for their field. And a large element of the community can fit into a small lecture theatre, as it did last week at the Synthetic Biology 2.0 conference at the University of California, Berkeley (see page 388).

But some indicators speak differently. To participate in the meeting was to witness an inspiring interdisciplinary festival of ideas and the central one of supplementing biology's attempts to understand 'life as it is' with systematic explorations of 'life as it could be' has undeniable élan. The field has attracted venture capitalists, Nobel laureates, acres of newsprint and Craig Venter (although there are some who would dispute whether any or all of these correlate with true worth).

Synthetic biology is also important enough to have attracted enmity. The Berkeley meeting was greeted by an open letter from 35 groups, claiming standing in 60 countries, that denounced the ambitions of synthetic biology and objected to the idea that its practitioners might institute structures of self-governance to mitigate some of its inherent risks - an idea mooted before the meeting, but one that remains an aspiration rather than a fixed intention.

The most powerful of the field's intellectual attractions is its bottom-up nature. Previous attempts to alter or improve on nature have been top-down, starting off with a whole, functioning organism and tweaking it, whether through selective breeding, by the addition of transgenes, or with a vaccine to focus the immune system. But in the light of the emerging technological possibilities of gene synthesis, synthetic biology aspires to work from the bottom up, building things from scratch, to remake, rather than reshape, the world, starting with a blank sheet of paper.

Blank sheets of paper are, for most of us, rather scary. The currently ill-defined and potentially immense capacities of synthetic biology bring worries aplenty, from unintended consequences to deliberate malfeasance. One does not have to agree with the letter's authors to think that, despite offering the possibilities of great benefit, synthetic biology also raises some very significant concerns.

So although many of the specific issues raised in the open letter fail to compel agreement, the overall message that there are real concerns is a valid one. What seems less defensible is the letter's hostility to self-governance; its authors are, after all, keen that the issues be discussed, and implicitly that governance be exercised.

Self-governance need not and should not be exclusive - it does not preclude other forms of governance, any more than the possession of conscience makes redundant the strictures of law. It is hard not to suspect that the problem with self-governance from the point of view of the letter-writers is that it could go some way to addressing potential problems that would make good campaigning issues.

The ability of human societies to modify and transform biological systems will increase more in this century than it has
"Scientists who are keen to discuss the issues with the world are part of the solution, not part of the problem." in the hundred centuries since the dawn of agriculture, regardless of whether the transformation unfolds under the rubric of 'synthetic biology'. Or, at least, we must hope that it will - as the only credible alternative is a future in which massive social upheaval, armed conflict or natural disaster halts the progress of scientific knowledge. The challenge is to foster a matching, or at least sufficient, increase in the wisdom and accountability with which these abilities are used.

That challenge will require changes in the law and customs, in ideology and theology, and in education and economics. No scientific community can be expected to shoulder all that on its own, and nor should it. Scientists who are alive to the possibilities of change, anxious to keep their house in order and be seen to be doing so, and keen to discuss the issues with the world, are part of the solution, not part of the problem.

\section{Coping with complexity}

\section{A more detailed understanding of scientific concepts does not lead to simplicity.}

7 wo philosophers of science recently surveyed 500 geneticists to ask their opinion on whether 14 different sets of genetic information constituted a gene, or more than one gene. Fortunately, the bulk of the respondents felt able to answer the questions definitively. Less fortunately, their answers were inconsistent, with the sample often quite evenly split on the question of how many genes were actually present.

Sceptics might note a degree of unravelling here. Decades of discussion have left a rather widespread perception, embraced by the general public and the media, of the gene as a tightly defined entity that spells out an inescapable destiny filled with beauty and health or, more often, blemishes and disease.

Even among the medical profession and some scientists, a gene is a trusty and well-defined concept - a specific sequence of genetic 
information that, when converted into messenger RNA, encodes a protein. Following this line of thinking, all that medical researchers really need to do is link up those darned diseases with their underlying genes, and human biology would fall into place.

Among geneticists themselves, this notion has long been eclipsed. Where once scientists saw placid, lonely genes that mass-produce RNA transcripts, now they find a chaotic jumble of RNA generated from all over the genome and from outside conventional genes. They have little clue what this RNA is doing, and don't always know where one gene ends and the next begins (see page 399).

And anyway, forget about DNA, says a paper on page 469 of this issue; some RNA might also be ferrying information from one generation to the next.

For most geneticists, this complexity is a source of marvel and fascination - and employment. How dull their lives would be if, once the human genome had been sequenced, there were just genes and diseases to be linked, like one of those join-the-dots puzzles. The genetic code holds new allure - its four-letter sequence may have been documented but it contains deeper hidden ciphers, and geneticists relish the task of breaking them.

There remains a nagging concern, however, that some of these challenges will frustrate the hopes of earlier generations that the study of biology could reduce complex problems to a mechanistic understanding of the relationship between DNA and living things.

Indeed, the complexity of this relationship has got us to the point where geneticists find it hard to agree on an appropriate definition of a gene. They are also unsure whether genes themselves are worthy of the most attention, compared with other parts of the genome, or RNA or proteins, or the way they all interact together in different tissues. At the very least, a serious disconnect seems to have arisen between the real problems that geneticists are wrestling with, and the public understanding of what they do.

It falls on researchers to make sure that the gap doesn't grow too wide. That means conveying the complexity of the task more clearly and fighting the media's tendency to boil down complex investigation to the discovery of the gene for something'. Geneticists should not be afraid of using new words, such as transcripts or loci, if these serve them better and more accurately. The public can cope with such distinctions.

After all, 'gene' is just a word, and dictionaries can be revised. Bring on the complexity - biology would be boring without it.

\section{Carbon omissions}

\section{The European Union's greenhouse-gas trading system needs reinforcement.}

W hen the European Union (EU) started the world's first mandatory greenhouse-gas emissions trading system in January 2005, there was widespread scepticism about its prospects. Thousands of companies were allocated 'allowances' for emitting a given amount of carbon dioxide; if they produce more, they have to buy extra credits. The sceptics questioned whether prices would climb high enough to provide a real incentive for industry to invest in clean technologies, or for power producers to switch to less-carbon-rich energy sources.

Some of this criticism subsided when the price, as well as the volume of trading on the new market, began to increase. By the middle of last month, the price of credits to release a tonne of carbon dioxide had reached more than $€ 30$ (US\$39). Then the price fell sharply, on rumours of unexpectedly low industrial emissions in a number of EU countries. But although the European Commission officially confirmed on 15 May that EU industries emitted 44 million tonnes less carbon dioxide in 2005 than they had been allocated, the predicted market meltdown failed to materialize (see page 405).

There are lessons to be learned from this month's market turmoil. Clearly, the European Commission, which is in charge of approving each member state's emissions allocation, over-allocated such rights for the initial trading period, from 2004 to 2007. But that is no reason to fear for the market's survival - it is normal, in the history of using such markets to control pollutants, for regulators to aim low and then turn up the heat as more experience is gained.

It is equally clear that administrative questions regarding the estimation, allocation and verification of emissions have yet to be fully resolved. Reporting and verification methods vary from country to country, with some, including Poland and Italy, admitting that their national registries aren't yet functioning.

Additionally, the basis of allocating emissions rights to different sections of industry isn't sufficiently clear or logical, and can actually hurt growth sectors that have actively sought to cut emissions but whose efforts are not rewarded by the system. A British-led initiative to update the allocation system has unfortunately come to nothing.

These issues need to be addressed if emissions trading is to remain viable and reach beyond the EU. A review of technological improvements in pollution control made since 1990 - the baseline year for the allocation assessment is needed, along with greater harmonization of the allocation and verification processes. Independent inspectors accredited by the European Commission must be granted full access to facilities across the EU.

Ultimately, the market will
"The market will have to be transparent, and the price substantialand reasonably stable, if industry is to take it into consideration when making investment decisions." have to be transparent, and the price substantial and reasonably stable, if industry is to take it into consideration when making investment decisions. A power company will not spend hundreds of millions of euros on carbon-sequestration facilities unless prices on the market signal clearly that it is economically sensible to do so. As such investments can take 20 years to bear fruit, industry also needs to know the system will still be around for the long haul.

The EU will in due course provide these assurances. The European Commission, in the meantime, must press on with the task of creating a firm and fair regulatory framework within which the market can thrive. 